\title{
From part to point cloud, the modelling of a 3D part
}

\author{
Diana Muntean ${ }^{1}$, and Octavian Bologa ${ }^{1, *}$ \\ ${ }^{1}$ Department of Machine and Industrial Equipment, Lucian Blaga University of Sibiu, Str. Emil \\ Cioran No.4, 550025, Sibiu, Romania
}

\begin{abstract}
The present paper focuses on the development of the composite materials in the automotiv industry by making a comparative analysis between a $3 \mathrm{D}$ model of the part and a real part made by a composite material, measuring the part using the point cloud. The aim is to obtain a high modeling and a more clear visualization of the composite material part.
\end{abstract}

\section{Introduction}

Living in a world that tends to develop the composite materials in the automotive industry, in this paper we tried to generate a comparison between a 3D model of the part and a real part made by a composite material, measuring the part using the point cloud. Using the probing session, it permits to capture point clouds in real time from a part made from UHMWPE that we inspected and do the rest of the analysis to compare it with the 3D model part. Using a specialized software the accuracy of the comparison is done through a large number of points that are obtained by probing. Converting a measured point cloud into a 3D polygonal model, we can provide to the part a higher modeling and a clearer visualization more clearly.

A point cloud can be defined as a "pixel cloud", because of the direct relationship between photomodelling and photography: each pixel of an image corresponds to a point of the cloud, this preserving the chromatic characteristics of the object inspected [1].

Inspecting a 3D model of a part means, inspecting a 3-dimensional model formed by a point cloud on the space coordinates: X,Y,Z.

\section{Composite material UHMWPE}

From the ancient times, the composite materials have been used to solve the demanding needs in life. For a material to be considered a composite, this it must be artificially created by combining a minimum of two different materials and the resulted material to have superior properties beside its "parents". A composite material is formed by two constituents: the matrix and the reinforcing phase.

\footnotetext{
*Corresponding author: octavian.bologa@ulbsibiu.ro
} 
The composite material ultrahigh-molecular-weight polyethylene (UHMWPE) was discover in 1920 by Hermann Staudlinger, this material was recognized only in 1956 to be valuable and it started to be commercialized. The UHMWPE is a polietilen that differentiates by other polimers due to the molecular chains that are very long and resistant. The mechanical properties of ths material are determined by the balance of crystal and amorphous areas, by the number of bundles from the cristal region and connection nature inside these amorphous regions. The elasticity module and the strength flow of UHMWPE are the sensitive mechanical properties at changing crystalline and orientation crystal [2].

Is known that UHMWPE is classified in: CESTILENE HD 500, CESTILENE HD 500 R, CESTICOLOR HD 500, CESTILENE HD 1000.

The material from the polietilen category that we want to study is UHMWPE CESTILENE HD 500, that has the next important properties: its color is black or white, has a medium molecular quantity about $500.000 \mathrm{~g} / \mathrm{mol}$, the density it $0.96 \mathrm{~g} / \mathrm{cm}^{3}$, his melt temperature varies between 130-135, traction flow limit is up to 28 MPA and the yieding module IS 1.350 MPA. This material has very good rigidity, tenacity and amortization properties very good, frazzle resistance and is low welding. Generaly this type of material is used in mechanical applications [3].

The material we chose is used in engineering industry, in flexible manufacturing lines, where positioning platforms for car body and special conveyer for the moving the car body exist, as named conveyance station from a work station to another.

Table 1. Properties of UHMWPE CESTILENE HD 500

\begin{tabular}{|c|c|}
\hline Properties & UHMWPE \\
\hline Colore & white/black \\
\hline $\begin{array}{c}\text { Molecular } \\
\text { mass }\end{array}$ & $500.000 \mathrm{~g} / \mathrm{mol}$ \\
\hline Density & $0.96 \mathrm{~g} / \mathrm{cm}^{3}$ \\
\hline $\begin{array}{c}\text { Melt } \\
\text { temperature }\end{array}$ & $130-135^{\circ} \mathrm{C}$ \\
\hline $\begin{array}{c}\text { Traction } \\
\text { flow limit }\end{array}$ & $28 \mathrm{MPA}$ \\
\hline $\begin{array}{c}\text { Yield } \\
\text { module }\end{array}$ & $1.350 \mathrm{MPA}$ \\
\hline
\end{tabular}

\section{Using a 3D model of a part}

By defining points in a three dimensional array we can create a 3D model of a part. This array is based on three axis: $\mathrm{X}, \mathrm{Y}$ and $\mathrm{Z}$, known as axis of geometric space where, different sets of these points are mathematically joined by lines to create polygons and the polygons joined to create objects. The result has been displayed as a wireframe model [4]. 


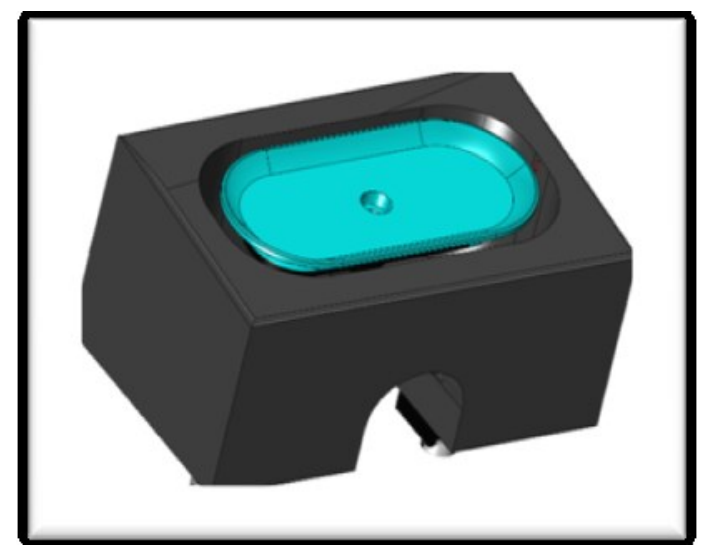

Fig. 1. 3D part model

Using a 3D model of a part, in this case a part that is a stand for a car door, we can measure it virtual, using the software PolyWorks Inspector to establish the value of the part in different surface points. The purpose of this inspection is to make a virtual analysis of the part in various points that are taken, to know its coordinates. Having a realistic and accurate $3 \mathrm{D}$ model of a part it is required not only for a good visualization of the model, but also to achieve a precise virtual measurement.

PolyWorks Inspector Probing has the ability to use a probing device directly on user interface to digitize parts. Probing devices include in our case an articular arm. The point clouds can be probed along the surface pf the part or on the boundaries of it. The point coordinates are measured on the axis: $\mathrm{X}, \mathrm{Y}$ and $\mathrm{Z}$, but using an articular arm it can optionally have normal I,J,K. [5]

Choosing a probing device is to collect a point cloud on the part so, the result is a data object that has $\mathrm{X}, \mathrm{Y}, \mathrm{Z}$ coordinates for every probed point.

The software PolyWorks has the capacity to change the position and orientation of the data object and to bring it in to a new coordinate system, that is needed. The 3D model of the part has it's coordinate system, a XYZ cartesian coordinate system, that allows the user to orient the part on the axe he wants.

To take a cloud point the $3 \mathrm{D}$ model of a part must have an origin and three axes that determine a world coordinated system for the part. In the 3D scene, the part is located in the world coordinated system and all the measurement results are aligned in the coordinate system.

To understand the cartesian coordinate system of a 3D model of a part it may be needed to know that every point of the surface inspected is represented by $\mathrm{X}, \mathrm{Y}, \mathrm{Z}$ values taken on three mutually perpendicular axes: X,Y,Z.

\section{Creating point clouds by probing inspection}

Using the most advanced inspection tool, PolyWorks Inspector, point clouds can be obtained by making a virtual or real probing inspection. To obtain a virtual data point cloud, it is necessary to select a virtual probing device from the software, but to achieve a real data point cloud is imperios to have a poliarticulat arm, in our case a FaroArm.

In measurement, an important issue is to reduce the number points that are outside the tolerance filed that can affect the mesurment. So, the clients in automotive industry use a number between 4-6 measurment points on the contact surface with the car body. Using a limited number of measurement points, with a tolerance indicated by the client, the software can indicate the deviation of the contact surface. 


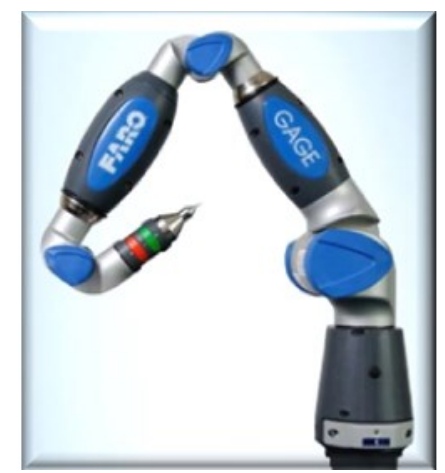

Fig. 2. Poliarticulat FaroArm.

In thie present paper we compare a part model from a weld robot station used in welding car boding and a 3D point cloud part. So we imported a CAD Model, IGS file format of the part we wanted to analyse. With the PolyWorks Inspector Probing we measured the deviatons of data point cloud that we have taken on the part with a $3 \mathrm{D}$ model of the part, so, the probing offered an object-oriented approach to the real measurement.

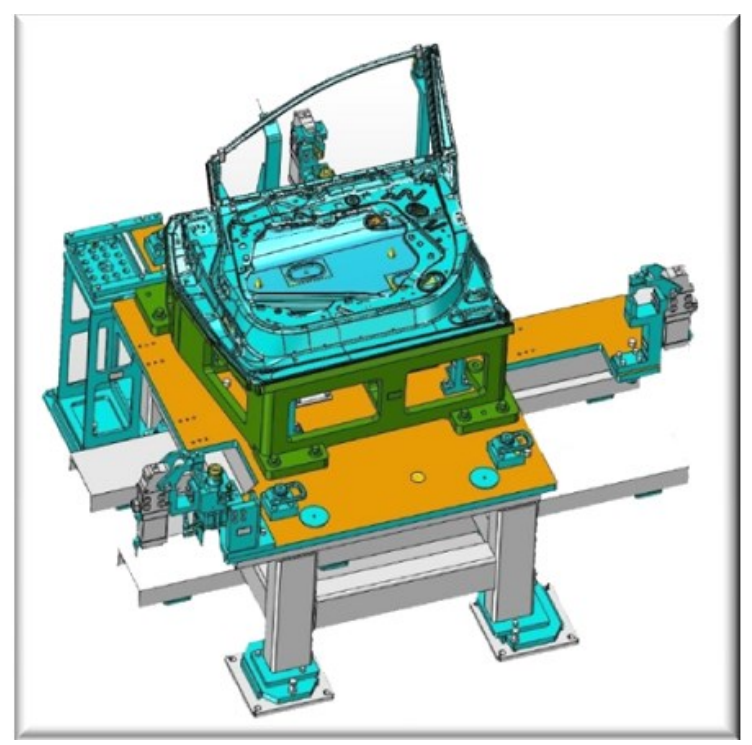

Fig. 3. Welding robot station - Car door.

Using parts made by a composite material like UHMWPE on a welding station, it is necessary that the tolerance of the parts to be tight because of the presents of the industrial robots that must take welding points on the sheets of the car door.

The stage of welding assembly lines are usually very highly automated, so in welding a car body the precision is an important factor in the composed process. [6]

Due to technological restrictions like quality in precision, process control constraints, etc., geometry welding tasks are required to be performed on the platform stations. [7]

Numerous experimental techniques have been proposed, patented or adopted and taken as standards. Cloud point is one of them, it is an easily measurable process, and taken an adequate method, it can be determinated and evaluated. 
A probing inspection, facing at the huge number of techniques available it would be tempting to suppose that cloud points are easily measurable and that adequate methods for their determination are available

When dealing with 3D point cloud data, it should be taken into account that, usually, a filtering of the raw point cloud data is carried out by internal software provided by the manufacturer of a device. [8]
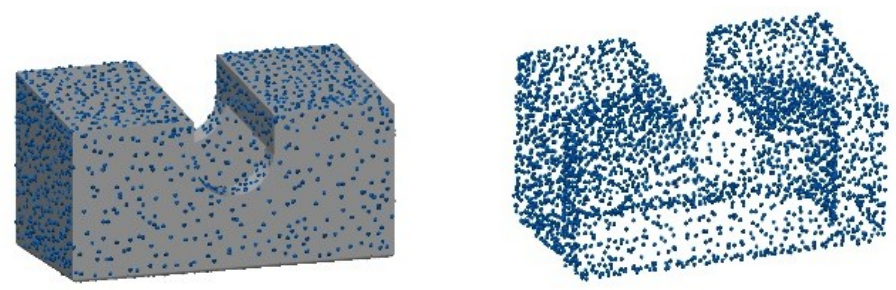

Fig. 4. Creating cloud points on the 3D model of the part.

Because the automotive industry assumes a high precision grade, it is necessary a high tolerance limit $\pm 0.3 \mathrm{~mm}$. In our case, in the inspected process, the part made of UHMWPE is measured in the tolerance limit $\pm 0.1 \mathrm{~mm}$. Inspecting the point can determine the nominal value, the measured value, and the deviation according to the required tolerance.

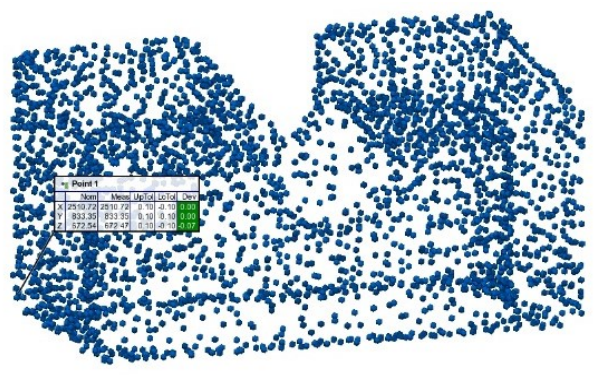

Fig. 5. Inspecting the point clouds.

\section{Reconstruction of the 3D model of the part from the point cloud}

3D model part reconstruction means the construction process of a $3 \mathrm{D}$ model of an object based on point cloud data. 3D point cloud data is used in applications for the automotive industry as a 3D model of a part reconstruction or geometry quality inspection.

A point cloud is an element of data points in a XYZ cartesian coordinate system. The structure of a point cloud is a simple $n$ by 3 matrix, where $n$ is the number of points and 3 are the $\mathrm{X}, \mathrm{Y}, \mathrm{Z}$ values. [9]

To use the $3 \mathrm{D}$ point cloud it we must obtain the value of every point cloud that composed the part. Analysing the errors of the point cloud distribution can be done with any software that can process the point cloud. The higher the number of the points are, the part resulted is more accurate. 


\section{Conclusions}

The purpose of this article is to present a type of process that a 3D part may need to model it. Probing inspection is one of these techniques to make a virtual or a real analysis of the part in very points that are taken, to know its coordinates. Taken the inspection of a 3D part model, can be known as the deviation of the part and it can be controlled in the process.

Companies adopt new techniques and try new ways to increase production efficiency for meeting the requirements of the global current production in the automotive industry.

A comparison between a geometric modelling process of a part to obtain the $3 \mathrm{D}$ model versus the obtaining process of the $3 \mathrm{D}$ model from the point cloud should provide important clues on the relationship between variables.

Getting a part through a geometric modelling process has a multitude of advantages, the main one being that with the necessary knowledge of design we can create any complex object we can

Getting a part through a cloud point is an easier and useful process, but to produce a correct part it may needed a dense point cloud.

Using one method or the other one depends only on the information we have about the piece and what we want to get.

\section{References}

1. M. Filippucci, Designarecon, 3(6), 50-63 (2010)

2. A. Tudor, T. Laurian, Un model de uzare abrazivă a polietilenei tip UHMWPE cu aplicație la protezele totale de șold, Simpozionul național cu participare internațional PRoiectarea ASIstată de Calculator PRASIC, (2010)

3. N. Fluoropolimeri, Poliamida, [Online]. Available: www.ptfe.ro. [Accessed 20 December 2018]

4. F. Remondino, Int. arch. photogramm. remote sens. spat. inf. sci., Vol. XXXIV-5/W10, 24-27 (2003)

5. Innovmetric, Essentials PolyWorks Inspector robing Package, 69 (2008)

6. G. Michalos, Makris, S., Papakostas, N., Mourtzis, D., \& Chryssolouris, G., in CIRP J. Manuf. Sci. Technol., 2, 81-91 (2010)

7. A. S. Michels, T. C. Lopes, C. G. S. Sikora, The Robotic Assembly Line Design (RALD) problem: Model and case studies, Elsevier, Brazil (2018)

8. M. Weinmann, Reconstruction and analysis of $3 D$ Scenes. From irregularly distributed $3 D$ points to object classes, Springer (2016)

9. J. Sun, Y. Jiang, J. Jiang, X. Bai, Triangular mesh construction based on point cloud matrix and edge feature extraction, Information Technology, Networking, Electronic and Automation Control Conference IEEE (2016) 